\title{
Optimum design of boost converter for charging the battery by non-conventional energy source
}

\author{
G. Prasanthi ${ }^{1}$, V. Sumalatha ${ }^{2}$ and A. Sudheer ${ }^{3}$ \\ ${ }^{1}$ Mechanical Engineering Department, JNTUA College of Engineering, Anantapur-515 002, India \\ ${ }^{2}$ ECE Department, JNTUA College of Engineering, Anantapur-515 002, India \\ ${ }^{3}$ Energy Systems, JNTUA College of Engineering, Anantapur-515 002, India \\ dr.smt.g.prasanthi@gmail.com; sumaatp@yahoo.com
}

\begin{abstract}
The utilization of battery can be improved by designing an appropriate charger capable of fast charging. Photovoltaic panel is used as input source for converter. The objective of this paper is to investigate the converter topologies and control techniques for fast charging of a battery which are required for its optimum design. A charging monitoring system is implemented based on converter technologies. Experimental simulation work is carried out in MATLAB-7.7b. A PI-gain controller feedback is used with reference voltage of $15 \mathrm{~V}$ for the ripple free output voltage.
\end{abstract}

Keywords: Converter technology, fast charging, MATLAB based monitoring system.

Introduction

The paper concentrates on practically developing an optimal boost converter model. A photovoltaic panel is taken as a voltage source in this present model (Rai, 2008). The main factors affecting the converter are photovoltaic panel output parameters, design of converter, environment and operating states of PV-panel (Maksimovic et al., 1996).

The following are the basic considerations for designing the converter:

i.Selection of battery type

ii.Design of charging method

iii.Design of fast charging.

Conventional charging methods include constantcurrent method, constant voltage method, and constant current-constant voltage method (two-step). This paper analyze the charging characteristics (viz. charging time, charging current, temperature, switching frequency \& pulse period) of constant-current method (Chattopadhyay et al., 2000).

The basic non-transformer-isolated topologies of converters are:

i. Buck (step-down)

ii. Boost (step-up)

iii. Buck-Boost (inverting).

The basic circuit diagram of a boost converter is shown in the Fig. 1 (Singh \& Khanchandani, 2007).

The circuit is analyzed by using

$\mathrm{V}_{\text {in }} \mathrm{D}+\left(\mathrm{V}_{\text {in }}-\mathrm{V}_{\text {out }}\right)(1-\mathrm{D})=0$,

$\mathrm{V}_{\text {out }}=\mathrm{V}_{\text {in }} /(1-\mathrm{D})$

Here, it is observed that $V_{\text {out }}>V_{\text {in }}$ always. This is called boost or step-up converter.

The power output of the boost topology is limited to about $150 \mathrm{~W}$ due to the high peak currents which stress the power switch and diode (Robbins \& Hawkins, 1994). The ability of the boost regulator to prevent the hazardous transients from reaching the load is also quite poor (Basu \& Underland, 2005). The boost converter (step-up) is used to step-up the voltage from photovoltaic panel for charging the battery.

\section{Simulation procedure}

MATLAB-7.7b based monitoring system is used to record the input voltage, output voltage and output current of boost converter. The current and voltage input parameters which are given to boost converter are drawn from photovoltaic panel. Actually in simulation procedure, this photovoltaic parameters are represented as repetitive sequence source block. The simulation circuit diagram for the boost converter shown in Fig. 2.

\section{Design procedure}

Voltage divider

The values of resistors and the other parameters are taken as per requirement for boost

converter. Output voltage of the converter is set by voltage divider $\mathrm{R} 1, \mathrm{R} 2$ and $\mathrm{R} 3$. A reasonable compromise for divider string overall impedance is a target of approx 1 $M \Omega$. R1 and R2 are typically split equally in value, to create the upper resistor in the divider so as to keep the maximum voltage across each resistor within the voltage rating of these devices $(250 \mathrm{~V})$. The voltage feedback with $\mathrm{PI}$ - Gain controller technique with the reference voltage of $15 \mathrm{~V}$ is shown in Fig. 3.

Pl-controller:

Output voltage for $\mathrm{RC}$ load when the reference output is set to $15 \mathrm{~V}$ is shown in fig. 4.

The following parameters are taken for the designing of boost converter:

$\mathrm{R} 1=1433.33 \mathrm{~K} . \mathrm{Ohms}$

$\mathrm{R} 2=100 \mathrm{~K}$. Ohms

$\mathrm{R} 3=300 \mathrm{~K}$. Ohms

Total resistance can be $R_{s}=251 \mathrm{~K}$ Ohms.

Current sense calculations:

Resistance (total), $R_{s}=251 \mathrm{~K} \mathrm{Ohms}$

$V_{\text {in }}(\mathrm{rms})=74$ Volts

Power dissipation in resistor is given by

$\mathrm{P}_{\mathrm{R}_{\mathrm{s}}}=\mathrm{I}_{\text {in(rms) }}^{2} \cdot \mathrm{R}_{\mathrm{s}}$

Therefore, Power can be calculated as
Research article

CIndian Society for Education and Environment (iSee)

\section{"Rapid battery charger"} http://www.indjst.org
Prasanthi et al. Indian J.Sci.Technol. 
Fig. 1. Basic circuit diagram of a boost converter

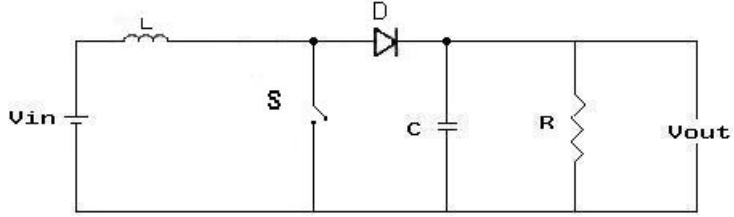

Fig. 3. Voltage feedback with Pl-gain controller

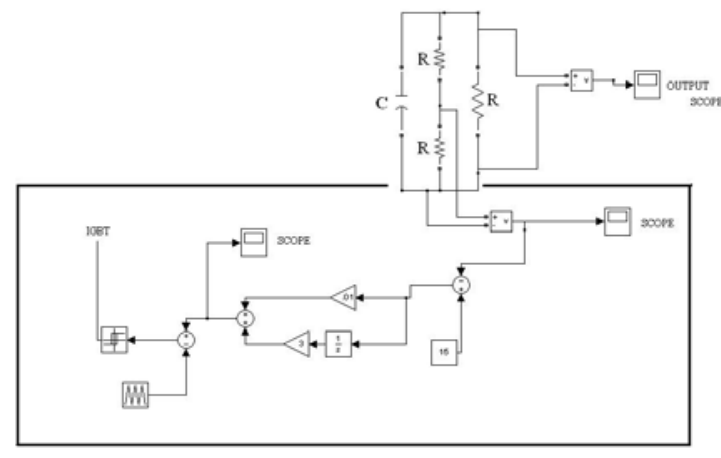

Fig .5. Block diagram of a boost converter in simulink

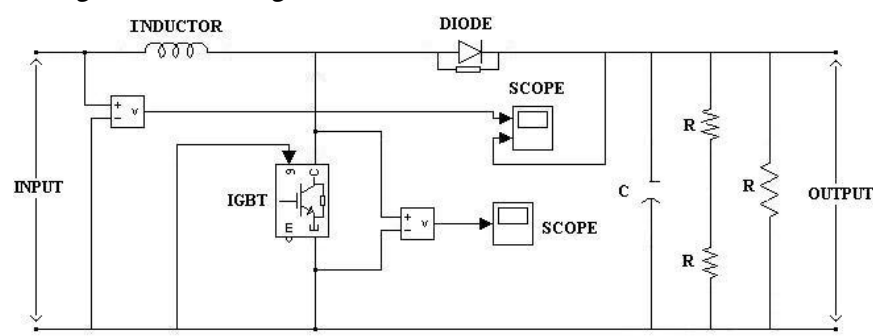

Fig. 7. Output current of $12 \mathrm{~A}$

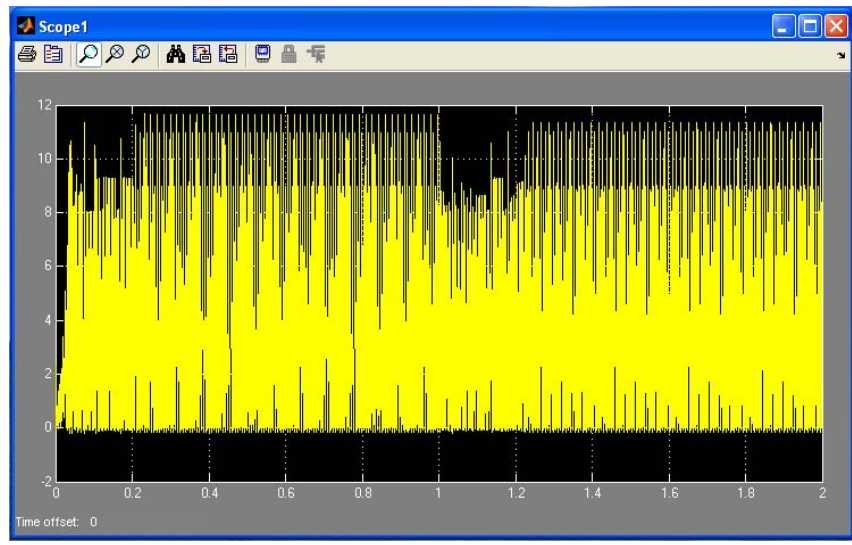

$P_{\text {in }}=12^{*} 12^{*} 251=361.44 \mathrm{KW}$.

The efficiency of input to PV panel is calculated as 0.83 by considering input voltage and current from source. $P_{\text {out }}=P_{\text {in }}{ }^{*}$ efficiency $=361.44^{*} 0.83=300 \mathrm{KW}$.

Simulation results

In the experimental set up, the input voltage given to the boost converter is between $14 \mathrm{~V}-74 \mathrm{~V}$.

Experimental results for an input voltage of $74 \mathrm{~V}$ are:

$\begin{array}{ll}\text { Output voltage } & : 422.4 \mathrm{~V} \\ \text { Output current } & : 12 \mathrm{~A}\end{array}$

Research article

(C)Indian Society for Education and Environment (iSee)
Vol. 3 No. 7 (July 2010)

ISSN: 0974- 6846

Fig. 2. Simulation diagram for the boost converter using the Pl-gain controller

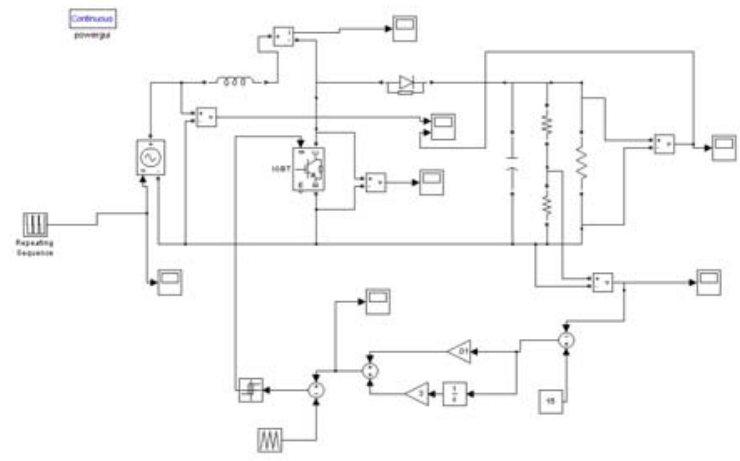

Fig. 4. Pl-gain controller output

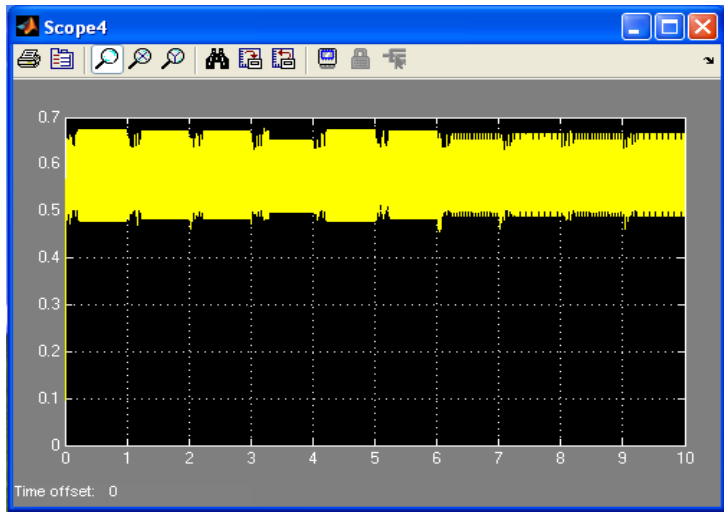

Fig. 6. Output voltage of $421.4 \mathrm{~V}$

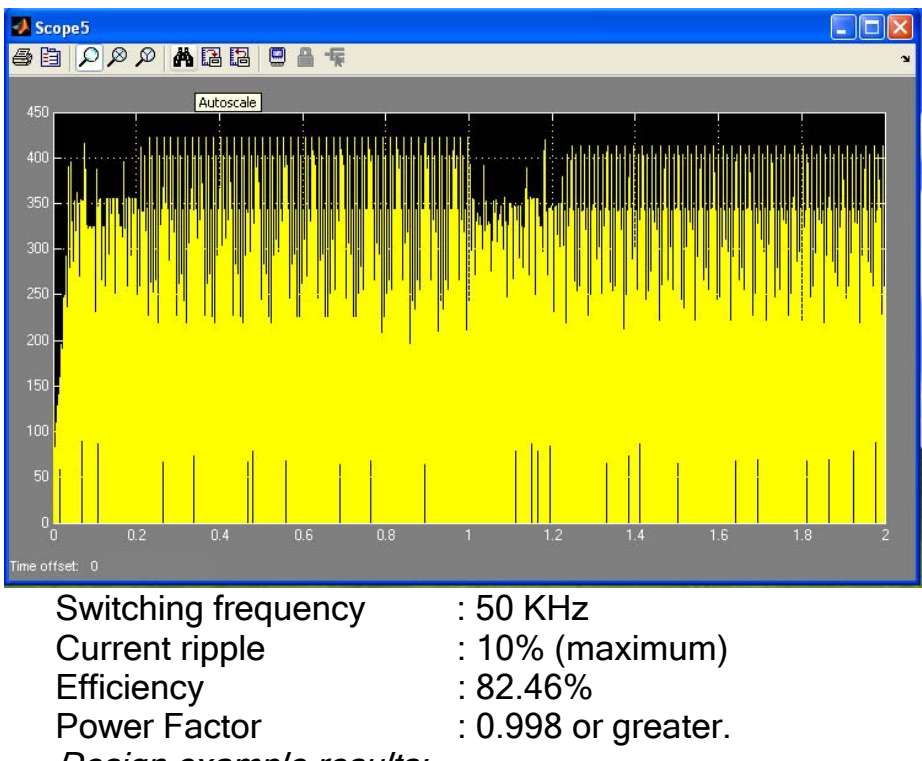

Design example results:

The Simulink model of the boost converter is shown in the Fig. 5.

From the simulation process, the results are shown in Fig. 6.

Output voltage vout $=421.4 \mathrm{~V}$

Voltage waveform: Scope: -5
"Rapid battery charger" http://www.indjst.org
Prasanthi et al. Indian J.Sci.Technol. 
Fig. 8. $V_{s}$ (of source) and $V_{\text {out }}$ readings at the primary voltage

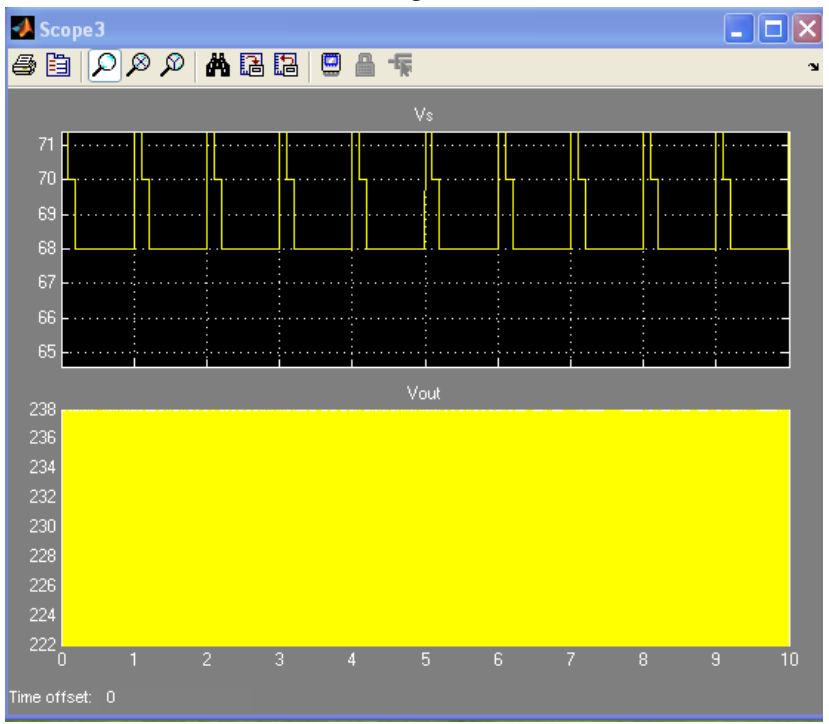

Fig. 9. The readings after auto scale

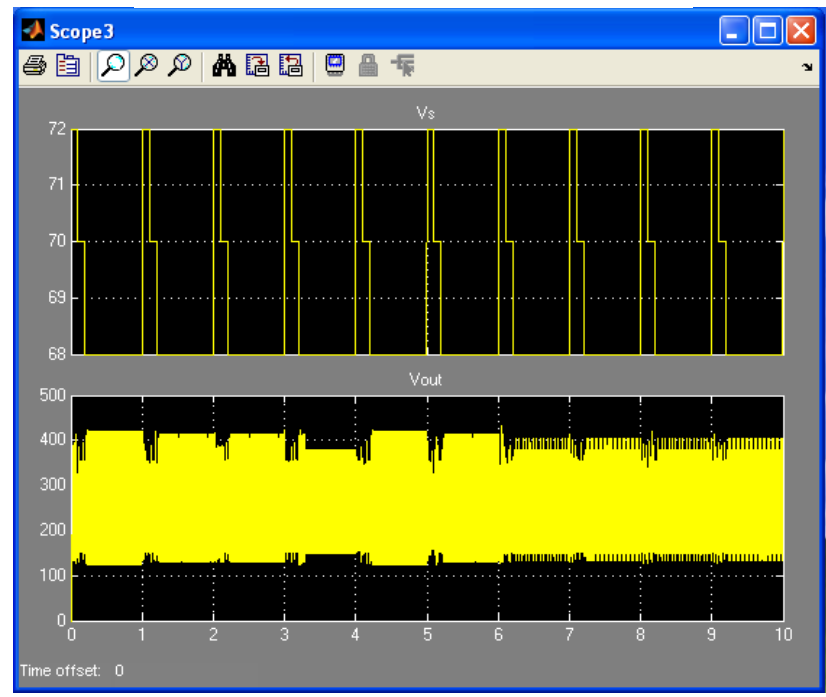

Fig. 10. At the IGBT switch voltage reading with ripple free

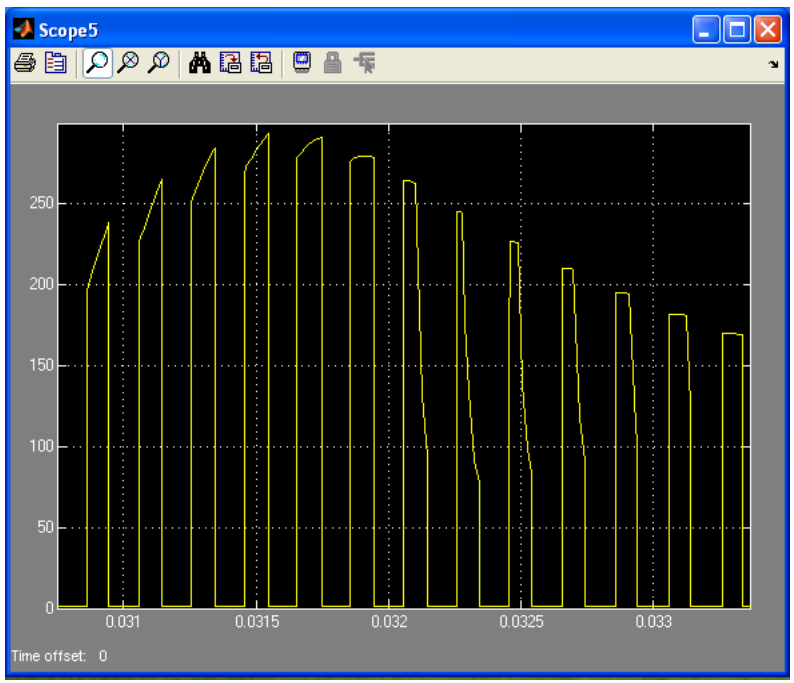

Research article

CIndian Society for Education and Environment (iSee)
"Rapid battery charger" http://www.indjst.org
Vol. 3 No. 7 (July 2010)

ISSN: 0974- 6846

Reading shown: 0 to $422.4 \mathrm{~V}$

From the simulation process, the output current is shown in Fig. 7.

$\mathrm{I}_{\text {Out }}=11.65 \mathrm{~A}(12 \mathrm{~A})$

Current waveform: scope: -1

Reading shown: 0-12 A

$\mathrm{Vs}$ (of source) and $\mathrm{V}$ out readings at the primary voltage are shown in Fig. 8, scope 3.

Simulation time: $0 \mathrm{~min}$

Simulation mode: Normal

After auto scale the reading is shown in Fig. 9, scope 4.

Simulation time: 10 min

Simulation mode: Normal

At the IGBT switch, voltage reading with ripple free is shown in Fig. 10, scope 5.

Majority of the converter design is based on low line current. That is the worst case condition for efficiency and input currents. Maximum input power can be calculated assuming a nominal efficiency at low line in boost converter. In some applications, such a high percent ripple may not be acceptable. Therefore, the value of the inductor is to be increased to decrease the ripple shown in Fig. 10.

\section{Conclusion}

Input voltage is taken from photovoltaic panel for the boost converter. Proper constant voltage converting topology is very important because it provides continuous rated output to the charger. The constant current charging scheme followed in the present work is simple and takes less time to execute. The output of the boost converter varies according to the input voltage of the converter giving ripple free voltage. We presented the optimum design of boost converter, which combined the monitor system features of fast charging and adjustable control.

\section{References}

1. Basu S and Underland TM (2005) Inductor design considerations for optimizing performance \& cost of continuous mode boost PFC converter. IEEE Trans. Power Electron. (11), 1133-1138.

2. Chattopadhyay S, Ramanarayanan $V$ and Jayashankar V (2000) A predictive switching modulator for current mode control of high power factor boost rectifier. Proc. $31^{\text {st }}$ Ann. IEEE Power Electronics Specialists Conf. (1), 371-376.

3. Maksimovic' D, Jang $Y$ and Erickson RW (1996) Nonlinear-carrier control for high-power-factor boost rectifiers, IEEE Trans. Power Electron. (11), 578-584.

4. Rai GD (2008) Non conventional energy sources, Khanna publishers, $4^{\text {th }}$ edn, $180-190$.

5. Robbins T and Hawkins J (1994) Battery model for over current protection simulation of DC distribution systems, IEEE Trans., (4), 307-314.

6. Singh MD and Khanchandani KB (2007) Power electronics, Tata Mc-Graw Hill, 2nd edn., 515-520. 